\title{
Aristotle's Golden Mean: Vague and Inapplicable?
}

\author{
Yuetong Zhou ${ }^{1, *}$
}

\author{
${ }^{1}$ Shenzhen College of International Education \\ *Corresponding author. Email: s19076.Zhou@stu.scie.com.cn
}

\begin{abstract}
The principle of the Golden Mean, according to which "every virtue of character lies between two correlative faults of vices" [1], presented in Aristotle' s Nicomachean Ethics, is one of the most controversial concepts among philosophers. Some appreciate it to be a substantive theory on virtue, while others demonstrate their criticism. This essay will examine two of the strongest criticisms against the theory of the Golden Mean: the accusation of uselessness and the accusation of semantic fallacy. Based on textual analyses of Nicomachean Ethics, the author defends Aristotle' s principle against these two criticisms, with the central argument that Aristotle' s metaphysical understanding of "form" and "matter" can respond to both accusations.
\end{abstract}

Keywords: "Nicomachean Ethics", “Aristotle", "Golden Mean”, "form and matter'

\section{THE TWO CRITICISM: OVERVIEW}

\subsection{The accusation of uselessness}

Bernard William calls the doctrine of Golden Mean "one of the most celebrated and the least useful parts of his [Aristotle's] system". What Bernard means entails, even without the concept of the Golden Mean, the other parts of Aristotelian system on virtue can still stand. Take the virtue of courage as an example. In Nicomachean Ethics, Aristotle uses the Golden Mean to define courage as the mean between "cowardice" and "rashness", but before that Aristotle articulates the region in which the virtue of courage applies -- in war, about vigor, and later on explains "five kinds of courage improperly so called" -- that is, define "courage" using genes and differentia [2]. Thus, even without the doctrine of the Golden Mean, Aristotle can still define the concept of courage properly with reference to the category it belongs, and the difference of it from other components inside the same category.

Essentially, the concept of Golden Mean is purely formal, and vague, according to Bernard's criticism. In no way had Aristotle even explained in his work how to spot out the mean between two extremes in everyday practice, and the whole reasoning is based on formal explanation of the virtue without any pragmatic reference. The only practical explanation is also in essence a formal and vague respond, that "The mean is hard to attain, and is grasped by perception, not by reasoning". Still, Aristotle fails to identify the specific approach to virtue in the concept of Golden Mean practically, since "by perception" is per se vague and formal.

Some Aristotelian scholars speak in Aristotle's favor, that the doctrine of Golden Mean is applicable only when accompanied by other parts of the Aristotelian framework on virtue and human reason, such as intuitive reason. Critics such as Bernard, in respond, point out the other parts of Aristotelian ethics are still formal in itself, including the theory of intuitive reason. The critics may accuse this theory, even combined with the concept of Golden Mean, of being still inapplicable, for no specific standard is provided whatsoever. Intuition can be wrong and unpredictable compared to reasoning, and Aristotle is simply confusing his audiences by using formal but not substantive theories throughout the whole book of the Nicomachean Ethics.

Some further accusations originated from the uselessness argument are as the following. The doctrine of the Golden Mean, due to its vagueness, can be misleading. One of the examples is a type of logical fallacy called Justification Through Canceling. Since the Golden Mean is only comparing the conduct to other two extremes, anyone can then justify their actions as long as their find two correspondingly more extreme phenomena. A bully can assure the victim of "getting less than deserving", and justifies the misconduct through that comparison simply by placing the action of 
bullying in the mean of two more severe actions [3]. Another type of misuse can be the instance when politicians manipulate the Golden Mean Principle in their favor. For example, Winston Churchill before WWI justified his policies in the name of moderation to convince the public of his decisions, which are in fact, extreme and demonstrated political wilderness. Therefore, proving something to be moderate is far from proving it to be virtuous.

\subsection{The accusation of semantic fallacy}

Similarly, another type of criticism also blamed the concept of Golden Mean for being non substantive by claiming that Aristotle is confused about the meaning of the "Good", attributing the confusing characteristic of the Golden Mean principle to the semantic fallacy.

The word "Good" can have, among others, two meanings, one means efficiency and another virtue. The underlying assumption of the Golden Mean Principle, the Ergon (function) Argument practically likens human to machines, allocating the human race, like machines, with a "function" that we are bound to achieve as long as we desire to be a "good" or "virtuous" person. Yet, by achieving a specific Goal, or Ergon, Aristotelian view is making a judgment on human's effectiveness, instead of virtue. This is demonstrated further by the meaning of the Golden Mean. Aristotle spot out a location within a spectrum as a mean, compared to two extremes, and in this way, he is, according to the critics, using the Golden Mean as a "quantitative standards". On contrast, ethics, such as "good or bad, right or wrong, righteous or evil", can only be assessed in "qualitative term of this-but-not-that". Conclusively speaking, Aristotle misinterprets two meaning of the word "good", equating "effectiveness" (a descriptive and quantitative concept) with "virtuous" (a normative and qualitative concept). Therefore, one can conclude by the above analysis that, virtue shall not be the at the center of the two vices; instead, it lies directly opposite to the vice, and a human can possess the extreme type of virtue -- the best of it. This framework of understanding how virtue works is further supported by Sir David Ross's argument. The examples, including "courage is the mean opposed to cowardice and rashness", which Aristotle provided to back up his argument, is, strictly speaking, flawed. "It is unnatural to oppose courage to rashness as well as to cowardice. The opposite of courage is cowardice, and the opposite of rashness discretion." [4] Therefore, the example of virtues at the mean is begging the question, not capable of proving the principle of the Golden Mean.

In essence, the semantic fallacy accusation lies within David Hume's understanding of the difference between normative and descriptive statement. Hume argues the impossibility of making a normative statement out of a purely descriptive statement. For example, it is impossible to infer from the statement that "the clock is slower than the world clock" to that "the clock is bad". There is an underlying normative judgment from the first statement to the second one, and the normative standard can only be reached through intuition, rather than reasoning. Hume, in his work A Treatise of Human Nature, further explains that, in the court to judge whether a man's conduct is vicious, one can use reasons to explore facts of the case. However, to make a moral judgment out of the criminals' conduct "is not an object of reason." "The vice entirely escapes you, as long as you consider the object. You never can find it, till you turn your reflection into your own breast, and find a sentiment of disapprobation, which arises in you, towards this action." [5] Thus, David Hume concluded the nature of morality that "Vice and virtue, therefore, may be compared to sounds, colors, heat and cold, which, according to modern philosophy, are not qualities in objects, but perceptions in the mind".

Therefore, concluded from Hume's understanding of morality, what hides behind the semantic fallacy accusation of Aristotle confusing the meaning of "efficiency" and "virtuous", is the premise that from someone being effective in doing something one cannot reach directly to the normative conclusion that someone is virtuous. Insofar as the Golden Mean not qualified for being a moral standard as it considers "efficiency" instead of "goodness", the criticism casts doubt on substantiveness of the Ergon Argument and the concept of Golden Mean as well.

\section{WHAT IS THE GOLDEN MEAN IN NATURE?}

The basic concept of the Golden Mean exists before Aristotle's philosophical articulation, as one of the habits of the Greeks. The temple of Apollo at Delphi bore the inscription Meden Agan, "Nothing in excess". Yet it was Aristotle's extrapolation in his book Nicomachean Ethics that made the Golden Mean doctrine glitter in intellectual history. Aristotle reached conclusion of the Golden Mean by referring to the Ergon (Function) Argument, and the understanding that quantitative change can lead to a qualitative alternation.

Aristotle starts his Ergon Argument by allegories of various occupations and organism. "For just as for a flute-player, a sculptor, or any artist, and, in general, for all things that have a function or activity, the good and the 'well' is thought to reside in the function, so would it seem to be for man, if he has a function." Compared to carpenter and organism such as "eye, hand, foot, and in general each of the parts", which both have a specific function, it's reasonable to induct that human should also have a certain function. Aristotle identifies the function of the human as "activity of soul exhibiting virtue, and if there are more than one virtue, in accordance with the best and most complete". Thus, the 
Ergon Argument can be expressed in the equation of "for any $\mathrm{x}$, if $\mathrm{x}$ has an Ergon $\mathrm{y}$, then $\mathrm{x}$ will be a good $\mathrm{x}$ if and only if $x$ produces good instances of $y$ " [6].

Aristotle further demonstrates the Golden mean being the very approach to reach virtue and accomplish Ergon by using two analogies: art and bodily health. The painting of Mona Lisa by Leonardo da Vinci, considered a well-designed art, can exemplify how the Golden Mean constructs quantitative change into qualitative alternation. It's universally accepted that a work is considered an art only if it's complete. The completion is the sufficient condition for a work to be artistic, and any more or less paints on the painting of Mona Lisa can ruin the sense of art. Thus, in the example, more paints is excess, while less paints is defect, while the masterpiece produced by Leonardo reaches the Golden Mean between two extremes of amounts of paints. It's comprehensive, then, that a qualitative change -- the change in the specific amount of paints on the paper -- in the painting itself leads to the qualitative change of the painting -- changing the normal paper into a masterpiece of art. "Beauty is no doubt a quality, not a quantity; but the quality is reached and realized through quantity" [7]. This theory applies in bodily health as well. Human body being too hot or too cold is signal of disease, and of excess and defect of the bodily temperature. The temperature of approximately $36-37 * \mathrm{C}$ is, then, the Golden Mean of two extremes types of temperature, and the signal of healthy. Here, in terms of bodily health, as the quantitative temperature reaches a specific number, and arrives at the Golden Mean, the body then becomes a healthy one, varying qualitatively. "This performance of function [which positively defines health and cannot be expressed by quantitative ratio] is continuously conditioned by the maintenance of certain quantitative ratios in the material substratum concerned". Therefore, the Golden Mean is, in Aristotelian ethical system, a path to Ergon by varying quantitative features into qualitative characteristics.

In nature, the capability of altering a quantitative feature into a qualitative one underlines the Aristotelian metaphysics system, using the division of "form" and "matter". Matter means the materials composing the object, while form is an abstract concept that makes the object what it is, and distinct from others. For instance, a sculptor uses a large marble to create an art of sculpture. In this case, the marble is the matter to compose the sculpture, while the difference between the original marble and the final sculpture is demonstrated by the form: the form of sculpture is rendered to the marble by the sculptor's working. From this example, we can easily see how the variation from quantitative quality to qualitative quality underlines the division of forms and matter: the specific arrangement of the marble -- the quantitative feature, can turn the normal marble into a piece of art -- the qualitative feature. In
Aristotle's own word, the change will be essentially, the sculptor rendering the form onto the matter of marble to be a sculpture.

\section{DEFENSE OF THE GOLDEN MEAN}

The understanding of the metaphysical foundation of the Golden Mean concept is essential in rethinking the two accusations presented in part 1 . Since the two accusations point directly at the nature of the Golden Mean concept, as well as the underlying premise of the Nicomachean Ethics, the reference to Aristotelian metaphysics is the key to explore Aristotle's thoughts on virtue in general.

\subsection{The accusation of uselessness reconsidered}

How can Aristotle's detailed extrapolation of the Golden Mean rebut against Bernard William's uselessness argument? The accusation of uselessness can be summarized into two words: formal and nonsubstantive. I will attempt to demonstrate that, Nicomachean Ethics in general is indeed formal in itself, but being formal is different from being nonsubstantive. A thorough understanding of Aristotelian metaphysical stance can prove distinctively what the ideal virtuous life Aristotle is constructing in his work of Nicomachean Ethics through the concept of the Golden Mean.

As we've discussed in the Part two, Golden Mean is the approach with which human can reach the Ergon (function), while it relies on the metaphysical division of form and matter. Therefore, to call Aristotelian work of Nicomachean Ethics formal means the work aims in providing the direction of how to render form onto the material life. Just as how a painter gives a paper the form of an art by using lines and paints quantitatively, what Aristotle understands as Eudaemonia (happiness), the ultimate goal of human kind, is the combination of the accomplishment of both the form of life and the matter of life. The matter of life, on one hand, composed of the actual action in everyday life conducted by individuals, while the form of life, on the other hand, is what Aristotle wants to formulate in his work of Nicomachean Ethics. Specifically, indeed the whole book seems formal and thus vague at the first glance, but after noticing the basic metaphysics underlying behind the theory, the function of the whole theory won't seem vague at all. Clear analysis and discussion of the human soul, virtue, reasons as well as the political and philosophical happiness outlines Aristotelian interpretation of the form in which the state at Eudaemonia incorporates. That's why despite the whole theory being formal, the sophisticated but fulfilled system of Aristotelian virtue is recognized to be substantive for human conduct, and a typical of Greek philosophical intelligence.The understanding of 
metaphysical foundation of Aristotelian moral philosophy can also explain why Aristotle identifies the path to learn about specific virtuous conduct as intuition. Any artistic theories cannot possibly give artists directives on how to arrange paints and lines directly, but a painter is able to be a better artist equipped with those theories. Therefore, the concept of the Golden Mean, resembling artistic theories, doesn't intend to give pragmatic instruction to everyday life, rather it portrays the moral form of life for the audiences, helping them nurture their intuition in everyday practice to act in a certain way, which contributes to the fulfillment of the best form of life, as Aristotle suggests.

Based on this interpretation, other accuses originated by Bernard's criticism can be responded to. Is the theory useless in the Aristotelian ethical system, so should be cut out by Okham's razor? It cannot, as long as one learns the importance of the Golden Mean doctrine in terms of form-and-matter metaphysics. A painter gives the form of art to a piece of paper through reaching the Golden Mean of paints needed, converting the quality of the art through the usage of quantitative measures -- the amount of paint. This means to give an object its form, the doctrine of the Golden Mean will be inevitably referred to. To give a specific example, the virtue of courage presented in political life, is the mean of cowardice and rashness. Since some critics claim the forced opposition of courage and rashness, I would like to firstly do a clarification, putting the blame on the inaccuracy of the translation. Indeed, rashness is somehow more opposed to discretion, but what Aristotle implies is the overusing of vigor leading to improper form of life. Even though, as one of the criticism claims, that there is analysis of genes and differentia in the book, without the reference to the Golden Mean, Aristotle would fail to portray the form and proper state of the amount of vigor, and without the quantified analysis of the vigor itself, his cannot then convert it into qualified virtue to accomplish the Ergon. Therefore, the Golden Mean doctrine is crucial in constructing Aristotelian system of formal virtue as guidance for human conduct.

Meanwhile, misleading accusation would seem weak under close examination. In no way Aristotle suggests the relativism justification for an idea, and those using the doctrine of Golden Mean in their favor are simply profaning Aristotle's theories, since the whole theory is on the level of forms rather than matter of everyday conduct. It is worth pointing out, though, Winston Churchill implementing extreme politics in the name of moderation doesn't directly show the weakness of Aristotle's theory being prone to misleading and inapplicable, as Aristotle in no way objects exclusively radical approaches to achieve a certain purpose politically. Still, the whole theory of Golden Mean is at formal level, and it is the people who misinterpret and manipulate the theory that we should blame, instead of the theory itself.

\subsection{The accusation of semantic fallacy reconsidered}

From the perspective of the formal and material distinction in Aristotelian metaphysics, the accusation of semantic fallacy narrows down to the debate on whether description statement entails a normative judgment. Aristotle, directly clashed with David Hume, will answer equipped with his concept of the Golden Mean and his Ergon argument specifically, that yes, it can.

The example of art and bodily health in Part 2 exemplifies how quantitative standard -- a positive statement and objective description of facts, can influence the qualitative feature -- a normative and "subjective" judgment, as Hume would say, and I further explain the variation underlines the distinction of form and matter. Therefore, as quantitative change of specific features can lead to a qualitative alternation, the positive argument on Ergon and the Golden Mean can entails a normative judgment. This is because Ergon is the ultimate purpose and Eudaemonia of human, which shall be a normative judgment itself, and the Golden Mean, despite being a positive description, serves as the path to reach the normative statement.

Another question may be posed on the Ergon argument itself, that the extrapolation of comparing human kind with the organism and occupation to prove the existence of Ergon is still a positive statement, but why the potentiality and function of human nature being so means it is virtuous if human kind reaches the state of it? Isn't that still a normative statement out of nowhere but intuition, that something deemed to be so means that it's virtuous? My respond is in two folds: First, it is not purely out of intuition. Aristotle has made use of the practical examples in the reasoning as I suggest above, and it's to the common sense that something achieving its purpose means it's a "good" thing. For human, then, people achieving Eudaemonia means the individual being a "good" human, which also means virtuous. It's also interesting to notice that in this case Aristotle actually closes the gap between something being effective in achieving its goal, and something being good. If the one achieving the goal specifically designed for it, then it's a good one, simply because the goal is desirable. Second, indeed there will always be a gap between normative statement and positive description if one sticks on claiming that achieving the desirable goal is far from being "good", and from this perspective Aristotle's work does entail the fundamental common sense unproven, yet doesn't impede his theory being convincing and substantive. 


\section{CONCLUSION}

This essay defends the necessity of the Golden Mean concept in Aristotelian Ethics against two commonlyraised criticisms, answering the criticism of uselessness and the criticism of semantic fallacy after demonstrating the Aristotelian Ethics's metaphysical principle.

The author reexamines the Golden Mean concept by extrapolating the Ergon Argument and point out that the Golden Mean constitutes an effective approach to accomplish the Ergon. Using examples from painting and bodily health, the author argues that qualitative changes of matters composing a particular activity can lead to qualitative variations of forms. Therefore, the Golden Mean concept succinctly encapsulates Aristotelian metaphysics into ethics by elucidating an approach of reaching Ergon, rendering a perfect form to human life by facilitating changes in actions or attitudes quantitatively.

The Aristotelian Metaphysics understands the unity of the subject in terms of both matter and form. Therefore, the concept of Golden Mean in no way lacks practicality since it functions as the path to render forms onto the matter. Meanwhile, the Aristotelian Metaphysics readily illustrates how quantitative and qualitative judgment are interlinked, so criticism of the semantic fallacy also doesn't stand.

\section{ACKNOWLEDGMENT}

The professor Siyi Chen from the Peking University gave abundant constructive suggestions for this paper.

\section{REFERENCES}

[1] Bernard Williams, "Ethics and Limits of Philosophy”, in: Routledge, 2006, pp36

[2] Aristotle, "the Nicomachean Ethics", translated by David Ross, in: Oxford University Press, 2009

[3] Kenneth Hamilton, "the false Glitter of the Golden Mean”, in: The Dalhousie Review, 1963

[4] Sir David Ross, “Aristotle”, in: Routledge, 2005

[5] David Hume, A treatise of Human Nature, The Floating Press, 2009

[6] Alfonso Gomez-Lobo, "A new look at the Ergon Argument in the Nicomachean Ethics", in: The Society for Ancient Greek Philosophy Newsletter, 1998

[7] J.T. Stocks, "The Golden Mean", in: Oxford Journals, 1931 